Supplementary Information

\title{
A solid 3D Li-S battery design via stacking 2D conductive microporous coordination polymers and amorphous Li-S layers
}

\author{
Guoping Gao, Fan Zheng, Lin-Wang Wang*
}

Materials Sciences Division, Lawrence Berkeley National Laboratory, Berkeley, California 94720, USA. E-mail: lwwang@,1bl.gov 


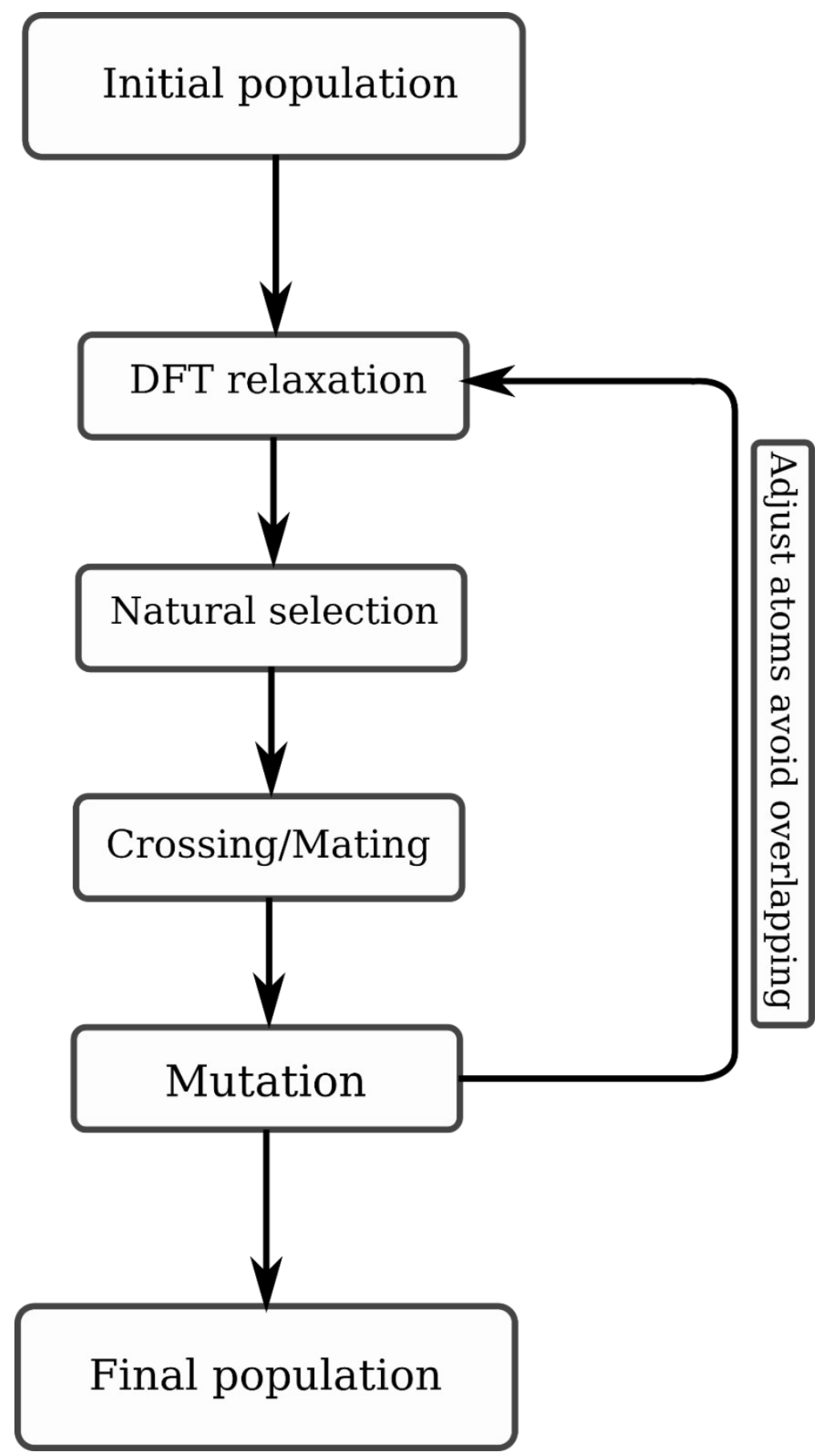

Figure S1 The process of the in-house global minimum structure search code.

In this optimization scheme, each generation contains 10 structures. One major feature is to generate new structures of the absorbed molecule/cluster, while keeping the structure of the substrate unchanged (although it will be moved during relaxation). The initial generation for each structure is obtained with random atomic $\mathrm{Li}$ and $\mathrm{S}$ positions on fixed $3 \mathrm{D} \mathrm{Mn}-\mathrm{HAB}$. DFT relaxations for all the 10 structures are performed, and the energies of the relaxed structure are sorted from lowest to highest. By natural selection, we pick up two structures out of the whole population to 
form a pair for crossing. The probability of picking structure $i$ is controlled by the fitness factor as $\exp \left(-\lambda^{*}\left(E_{i}-E_{\min }\right) /\left(E_{\max }-E_{\min }\right)\right)$. The $\lambda$ is set to 2 obtained from Ref ${ }^{1}$. For the crossing process of the two structures, we randomly choose $\mathrm{Li}$ or $\mathrm{S}$ atoms from each structure and rotate the whole structure along the $z$-axis so that the picked atoms are along the $x$-direction for both structures. The crossing is processed by coding all the $\mathrm{Li}$ and $\mathrm{S}$ atoms of a structure into a 1-d array using the $\mathrm{x}$-component of the atomic coordinates. The number of $\mathrm{Li}$ and $\mathrm{S}$ atoms are re-counting so that they are conserved for each crossing/mating trial. By random selecting a point along with the two 1-d arrays, these two arrays are crossovered so that we can obtain a mated structure out of the two structures. A pre-relaxation is performed via a steep-descent method to avoid too-close atoms. Then DFT relaxations are used to relax all the child structures and obtain their energies. We then repeat the natural selection as mentioned above. As energies of the lowest structure do not change after many generations, we believe the global minimum structure is obtained.

\section{The enlarged views of $\mathrm{Li}_{5} \mathrm{~S}_{8}{ }^{*}$ and $\mathrm{Li}_{20} \mathrm{~S}_{8}{ }^{*}$.}
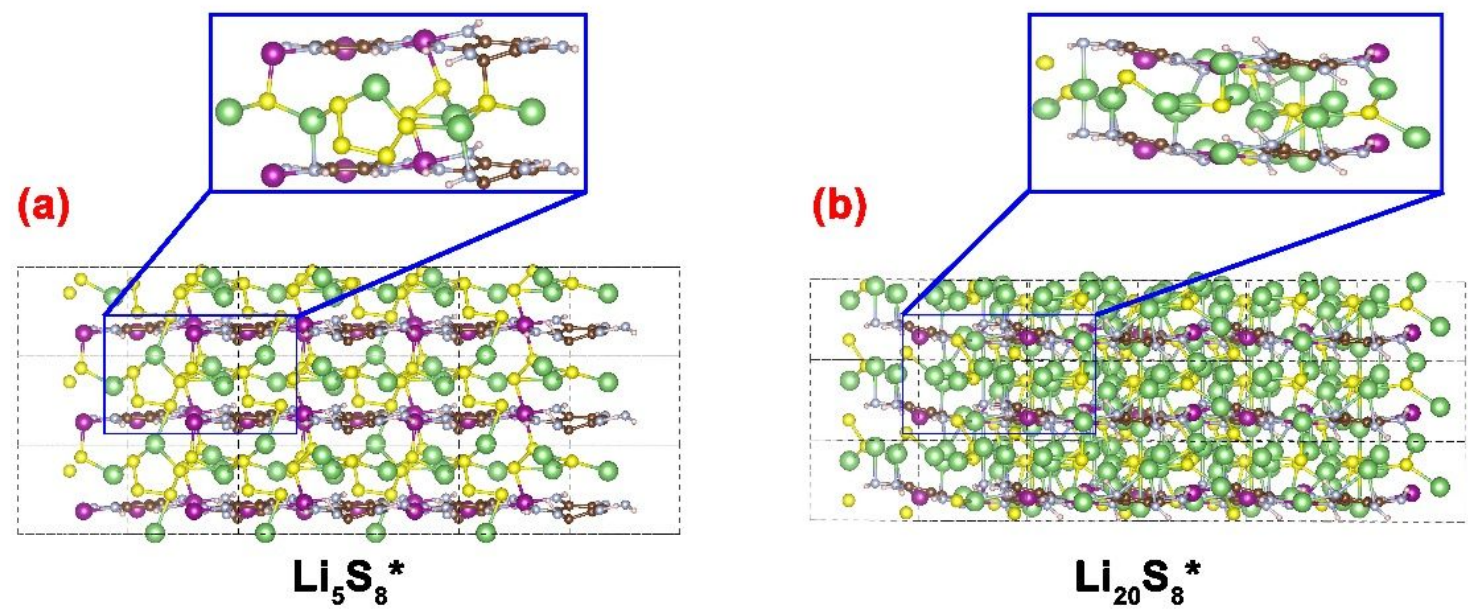

Figure S2 the enlarged views of $\mathrm{Li}_{5} \mathrm{~S}_{8}{ }^{*}$ and $\mathrm{Li}_{20} \mathrm{~S}_{8}{ }^{*}$. The bond length cut-off for $\mathrm{Mn}-\mathrm{S}$ is $2.4 \AA$, for $\mathrm{N}$-Li is $2.4 \AA$, for S-S is $2.4 \AA$, for $\mathrm{Li}-\mathrm{S}$ is $2.6 \AA$, and for possible $\mathrm{Mn}-\mathrm{Li}$ is $2.6 \AA$. 
3. The Band structures of Mn-HAB, Mn-HAB- $S_{8}, M n-H A B-L_{5} S_{8}, M n-H A B-L i_{10} S_{8}, M n-H A B-L_{15} S_{8}$, and $\mathrm{Mn}-\mathrm{HAB}-\mathrm{Li}_{20} \mathrm{~S}_{8}$.

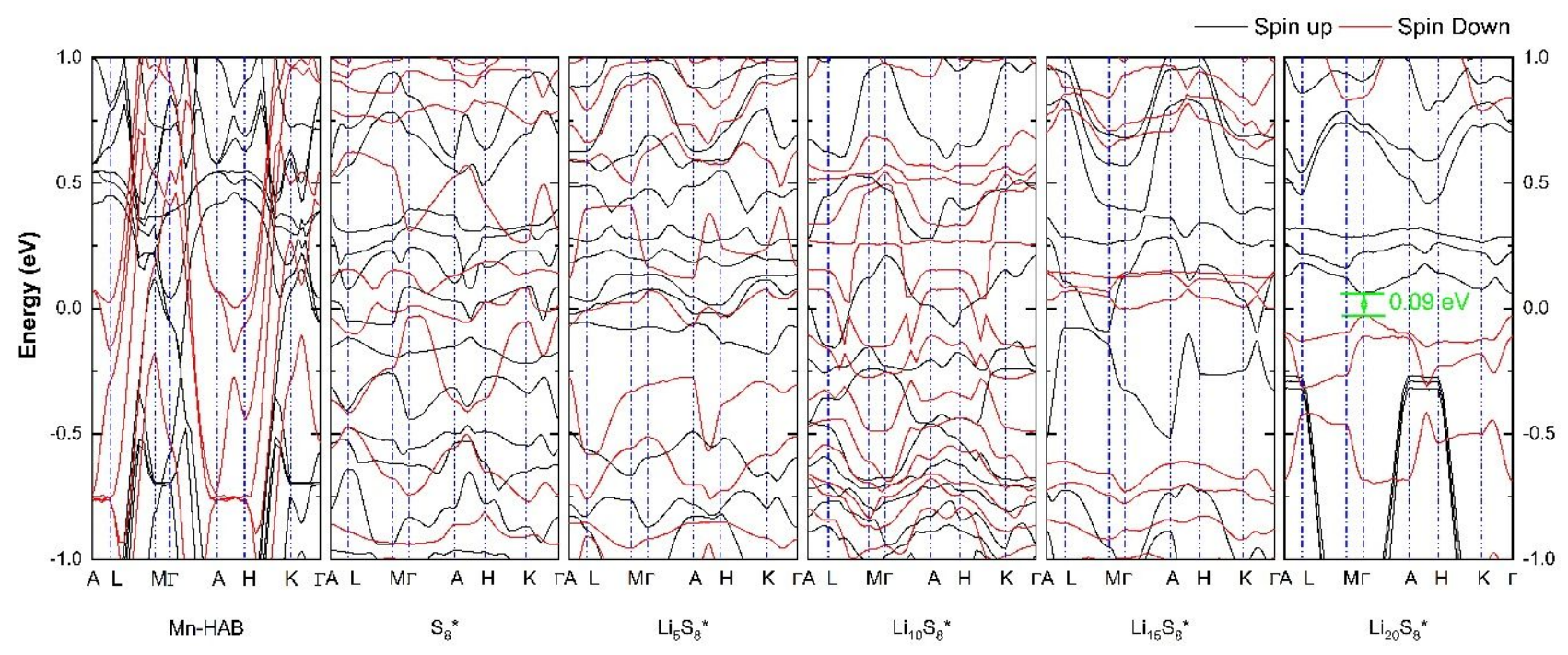

Figure S3. Band structures of Mn-HAB, Mn-HAB- $\mathrm{S}_{8}, \mathrm{Mn}-\mathrm{HAB}-\mathrm{Li}_{5} \mathrm{~S}_{8}, \mathrm{Mn}-\mathrm{HAB}-\mathrm{Li}_{10} \mathrm{~S}_{8}, \mathrm{Mn}-\mathrm{HAB}-\mathrm{Li}_{15} \mathrm{~S}_{8}$, and Mn-HAB-Li ${ }_{20} \mathrm{~S}_{8}$. The Femi level is set to zero.

\section{The barrier of Li migration on the graphene}
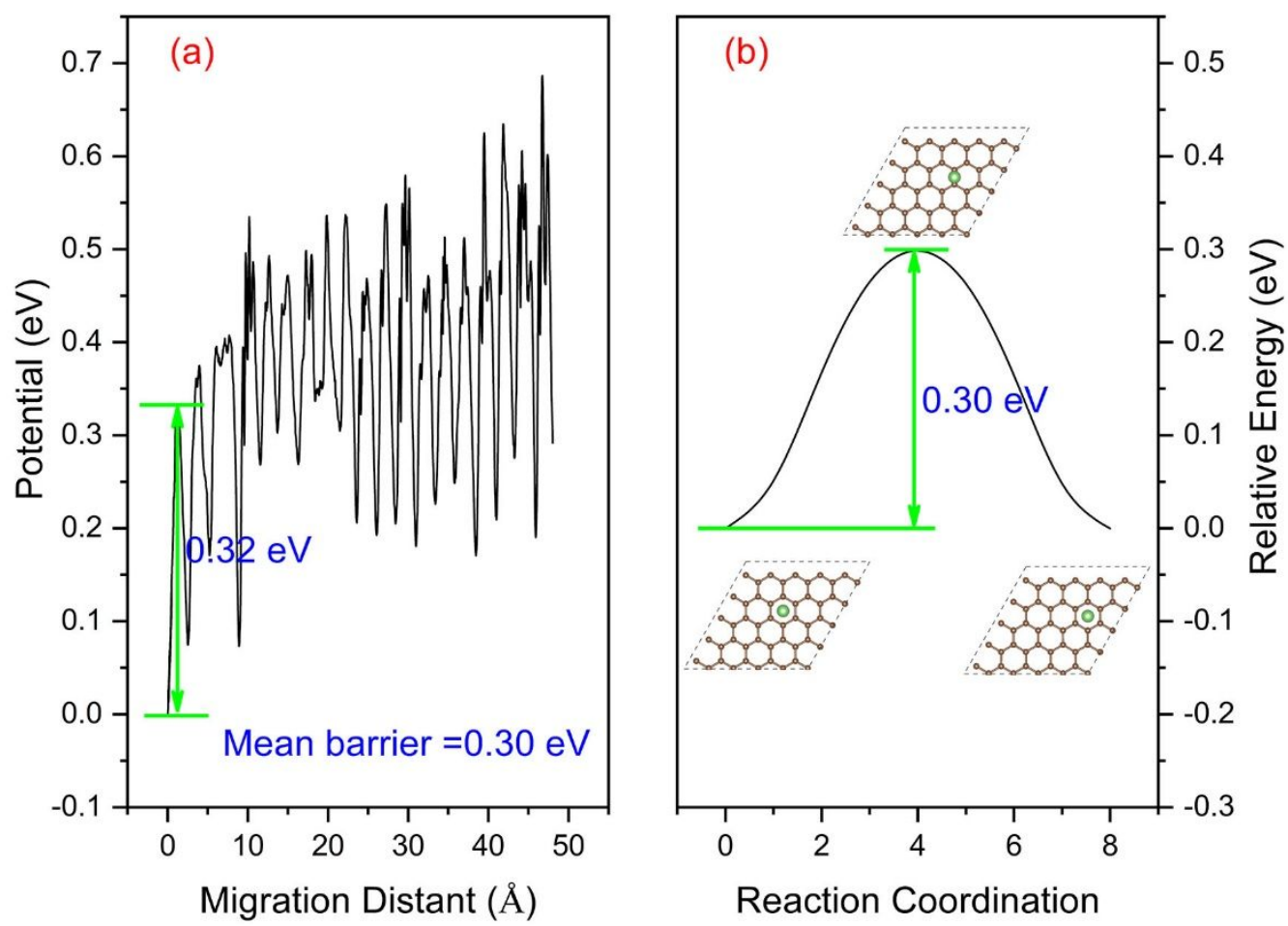

Figure S4 The barrier of Li migration on the graphene obtained by our model (a) and NEB calculation (b). 
5. The fitted potential evolutions of Li migration in Mn-HAB-Li5S8, Mn-HAB-Li10S8, and Mn-HAB-Li15S8.
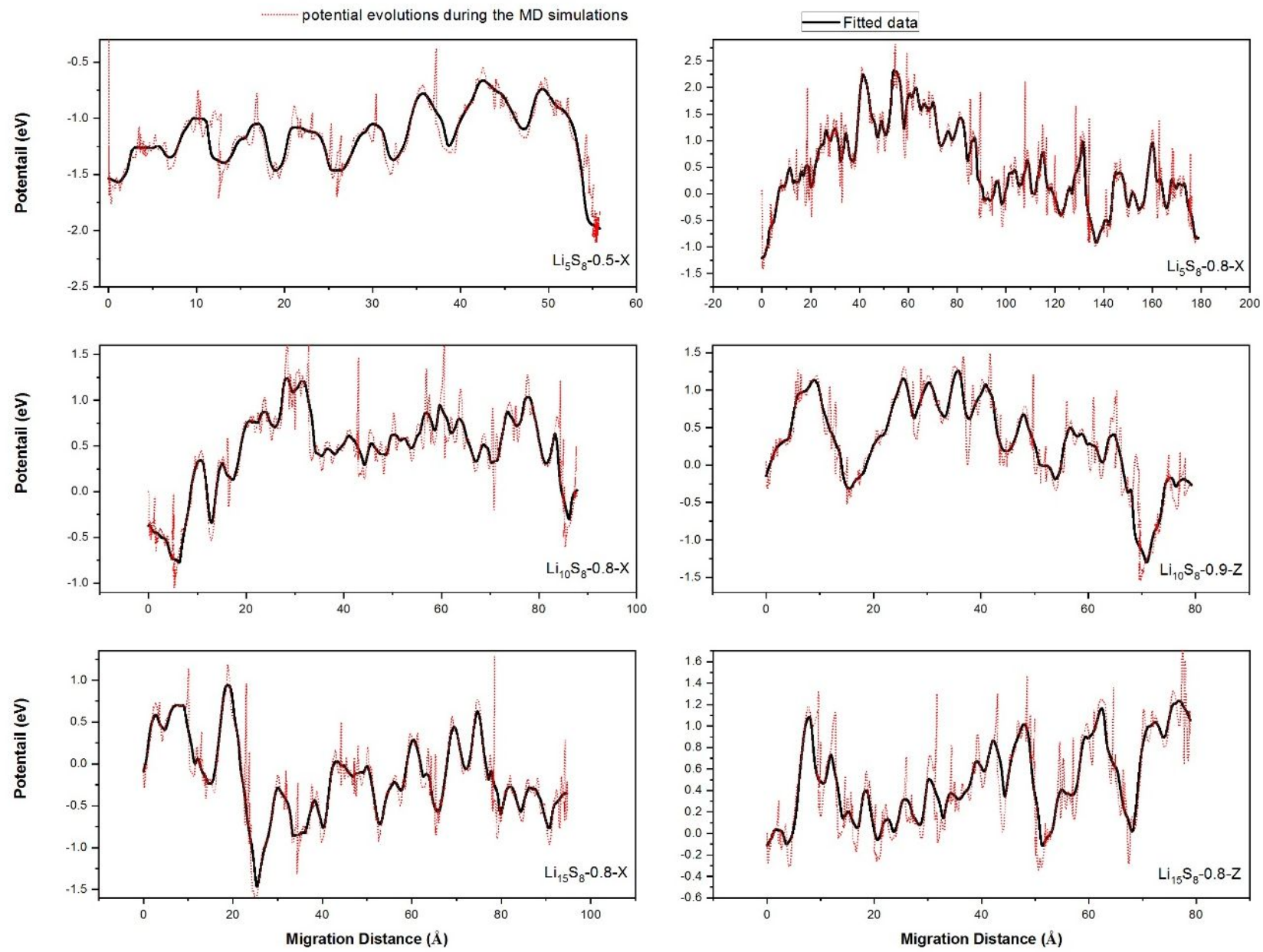

\section{Key parameters for Li diffusion}

Table S1 The average barriers and diffusion rate of Li migration in Mn-HAB-Li $\mathrm{S}_{8}, \mathrm{Mn}-\mathrm{HAB}-\mathrm{Li}_{10} \mathrm{~S}_{8}$, and Mn-HAB-Li ${ }_{15} \mathrm{~S}_{8}$.

\begin{tabular}{|c|c|c|c|c|c|c|}
\hline & $\mathrm{Li}_{5} \mathrm{~S}_{8}-0.5-\mathrm{X}$ & $\mathrm{Li}_{10} \mathrm{~S}_{8}-0.8-\mathrm{X}$ & $\mathrm{Li}_{10} \mathrm{~S}_{8}-0.8-\mathrm{Z}$ & $\mathrm{Li}_{15} \mathrm{~S}_{8}-0.8-\mathrm{X}$ & $\mathrm{Li}_{15} \mathrm{~S}_{8}-0.8-\mathrm{Z}$ & graphene \\
\hline $\begin{array}{c}\text { Average } \\
\text { barrier }(\mathrm{eV})\end{array}$ & 0.42 & 0.46 & 0.52 & 0.61 & 0.55 & 0.30 \\
\hline $\mathrm{d}(\AA)$ & 6.93 & 7.31 & 6.61 & 6.76 & 6.57 & 3.28 \\
\hline
\end{tabular}


7. Comparison of lithium-ion diffusion coefficient from the present work with available literature data in Li-ion battery.

Table S1 The diffusion coefficient of different cathode and electrolyte

\begin{tabular}{|l|l|l|}
\hline Composition & Diffusion coefficient $\left(\mathrm{cm}^{2} \mathrm{~s}^{-1}\right)$ & Reference \\
\hline $\mathrm{Li}_{5} \mathrm{~S}_{8}-0.5-\mathrm{X}$ & $6.36 \times 10^{-10}$ & This study \\
\hline $\mathrm{Li}_{10} \mathrm{~S}_{8}-0.8-\mathrm{X}$ & $1.21 \times 10^{-10}$ & This study \\
\hline $\mathrm{Li}_{10} \mathrm{~S}_{8}-0.8-\mathrm{Z}$ & $1.24 \times 10^{-11}$ & This study \\
\hline $\mathrm{Li}_{15} \mathrm{~S}_{8}-0.8-\mathrm{X}$ & $3.83 \times 10^{-13}$ & This study \\
\hline $\mathrm{Li}_{15} \mathrm{~S}_{8}-0.8-\mathrm{Z}$ & $3.33 \times 10^{-12}$ & This study \\
\hline graphene & $2.39 \times 10^{-8}$ & This study \\
\hline $\mathrm{LiNi}_{0.50} \mathrm{Mn}_{0.20} \mathrm{Co}_{0.30} \mathrm{O}_{2}\left(\mathrm{NMC}_{523}\right)$ & $4.5 \times 10^{-8}$ & 2 \\
\hline $\mathrm{LiNi}_{0.33} \mathrm{Mn}_{0.33} \mathrm{CO}_{0.33} \mathrm{O}_{2}\left(\mathrm{NMC}_{333}\right)$ & $5.5 \times 10^{-8}$ & 2 \\
\hline $\mathrm{LiFePO}_{4}$ & $1.8 \times 10^{-14}$ & 3 \\
\hline $\mathrm{LNMO}_{\mathrm{LLZO}(50: 1)}$ & $1.83 \times 10^{-10}$ & 4 \\
\hline $\mathrm{LiNi}_{0.5} \mathrm{Mn}_{1.5} \mathrm{O}_{4}$ & $6.43 \times 10^{-11}$ & 4 \\
\hline $\mathrm{a}-\mathrm{Li}_{3} \mathrm{PO}_{4}$ & $6.0 \times 10^{-13}$ & 5 \\
\hline $\mathrm{Cubic} \mathrm{LLZO}_{2} \mathrm{Al}$ & $\sim 10^{-9}$ & 6 \\
\hline $\mathrm{LiTi}_{2}\left(\mathrm{PS}_{4}\right)_{3}$ & $1.2 \times 10^{-7}$ & 7 \\
\hline $\mathrm{Li}_{10} \mathrm{GeP}_{2} \mathrm{~S}_{12}$ & $\sim 3.30 \times 10^{-8}$ & $8-9$ \\
\hline
\end{tabular}

\section{Reference}

1. Darby, S.; Mortimer-Jones, T. V.; Johnston, R. L.; Roberts, C., Theoretical study of Cu-Au nanoalloy clusters using a genetic algorithm. J. Chem. Phys. 2002, 116 (4), 1536-1550.

2. Amin, R.; Chiang, Y.-M., Characterization of Electronic and Ionic Transport in $\mathrm{Li}_{1-\mathrm{x}} \mathrm{Ni}_{0.33} \mathrm{Mn}_{0.33} \mathrm{Co}_{0.33} \mathrm{O}_{2}$ (NMC333) and $\mathrm{Li}_{1-\mathrm{x}} \mathrm{Ni}_{0.50} \mathrm{Mn}_{0.20} \mathrm{Co}_{0.30} \mathrm{O}_{2}\left(\mathrm{NMC}_{523}\right)$ as a Function of Li Content. J. Electrochem. Soc. 2016, 163 (8), A1512-A1517.

3. Prosini, P. P.; Lisi, M.; Zane, D.; Pasquali, M., Determination of the chemical diffusion coefficient of lithium in LiFePO ${ }_{4}$. Solid State Ion. 2002, 148 (1), 45-51.

4. Liu, W.; Shi, Q.; Qu, Q.; Gao, T.; Zhu, G.; Shao, J.; Zheng, H., Improved Li-ion diffusion and stability of a $\mathrm{LiNi}_{0.5} \mathrm{Mn}_{1.5} \mathrm{O}_{4}$ cathode through in situ co-doping with dual-metal cations and incorporation of a superionic conductor. $J$. Mater. Chem. A 2017, 5 (1), 145-154.

5. Kuwata, N.; Lu, X.; Miyazaki, T.; Iwai, Y.; Tanabe, T.; Kawamura, J., Lithium diffusion coefficient in amorphous lithium phosphate thin films measured by secondary ion mass spectroscopy with isotope exchange methods. Solid State Ion. 2016, 294, 59-66.

6. Hiebl, C.; Young, D.; Wagner, R.; Wilkening, H. M. R.; Redhammer, G. J.; Rettenwander, D., Proton Bulk Diffusion in Cubic $\mathrm{Li}_{7} \mathrm{La}_{3} \mathrm{Zr}_{2} \mathrm{O}_{12}$ Garnets as Probed by Single X-ray Diffraction. J. Phys. Chem. C 2019, 123 (2), 1094-1098.

7. Di Stefano, D.; Miglio, A.; Robeyns, K.; Filinchuk, Y.; Lechartier, M.; Senyshyn, A.; Ishida, H.; Spannenberger, S.; Prutsch, D.; Lunghammer, S.; Rettenwander, D.; Wilkening, M.; Roling, B.; Kato, Y.; Hautier, G., Superionic Diffusion through Frustrated Energy Landscape. Chem 2019.

8. Mo, Y.; Ong, S. P.; Ceder, G., First Principles Study of the $\mathrm{Li}_{10} \mathrm{GeP}_{2} \mathrm{~S}_{12}$ Lithium Super Ionic Conductor Material. Chem. Mater. 2012, 24 (1), 15-17.

9. Kuhn, A.; Duppel, V.; Lotsch, B. V., Tetragonal $\mathrm{Li}_{10} \mathrm{GeP}_{2} \mathrm{~S}_{12}$ and $\mathrm{Li}_{7} \mathrm{GePS}_{8}$ - exploring the $\mathrm{Li}$ ion dynamics in $\mathrm{LGPS} \mathrm{Li}$ electrolytes. Energy Environ. Sci. 2013, 6 (12), 3548-3552. 